Annales Geophysicae (2001) 19:773-781 C European Geophysical Society 2001

(5)

\title{
The variability of Joule heating, and its effects on the ionosphere and thermosphere
}

\author{
A. S. Rodger ${ }^{1}$, G. D. Wells ${ }^{2,3}$, R. J. Moffett ${ }^{2}$, and G. J. Bailey ${ }^{2}$ \\ ${ }^{1}$ British Antarctic Survey, Madingley Road, Cambridge CB3 0ET, UK \\ ${ }^{2}$ Space and Atmosphere Research Group, Department of Applied Mathematics, University of Sheffield, Sheffield S3 7RH, UK \\ ${ }^{3}$ Now at Electromagnetic Engineering and Test, W423, BAE SYSTEMS, Warton Aerodrome, Warton, Preston, Lancashire, \\ PR4 1AX, UK
}

Received: 10 January 2000 - Revised: 4 April 2001 - Accepted: 18 April 2001

\begin{abstract}
A considerable fraction of the solar wind energy that crosses the magnetopause ends up in the high-latitude thermosphere-ionosphere system as a result of Joule heating, the consequences of which are very significant and global in nature. Often Joule heating calculations use hourly averages of the electric field, rather than the time-varying electric field. This leads to an underestimation of the heating. In this paper, we determine the magnitude of the underestimation of Joule heating by analysing electric field data from the EISCAT Incoherent Scatter Radar, situated at the $67^{\circ}$ E magnetic latitude. We find that the underestimation, using hourly-averaged electric field values, is normally $\sim 20 \%$, with an upper value of about $65 \%$. We find that these values are insensitive to changes in solar flux, magnetic activity and magnetic local time, implying that the electric field fluctuations are linear related to the amplitude of the electric field. Assuming that these changes are representative of the entire auroral oval, we then use a coupled ionosphere-thermosphere model to calculate the local changes these underestimations in the heating rate cause to the neutral temperature, mean molecular mass and meridional wind. The changes in each parameter are of the order of a few percent but they result in a reduction in the peak F-region concentration of $\sim 20 \%$ in the summer hemisphere at high latitudes, and about half of this level in the winter hemisphere. We suggest that these calculations could be used to add corrections to modelled values of Joule heating.
\end{abstract}

Key words. Ionosphere (eletric fields and currents; ionospheric disturbances; polar ionosphere)

\section{Introduction}

About $10^{12} \mathrm{~W}$ crosses the dayside magnetopause when the interplanetary magnetic field has a southward component. This power is then redistributed through the closely-coupled ionosphere-magnetosphere system. The most spectacular

Correspondence to: A. S. Rodger (a.rodger@bas.ac.uk) display of the effects of this power redistribution occurs during the magnetospheric substorm when $10^{11} \mathrm{~W}$ can be deposited in the thermosphere. Many studies have tried to determine the energy deposition into its three main elements, Joule heating, particle heating and energy storage in the ring current, but there is no consistent partitioning, and the processes which affect it are not understood. For example, during the much studied storm of 2-6 November 1993, about $15 \%$ of the energy went into the ring current (Kozyra et al., 1998), $15 \%$ was deposited directly via particles, and $70 \%$ was deposited through Joule heating (Sharber et al., 1998). Enhanced energy deposition into the ring current during large storms $(D s t<-240 \mathrm{nT})$ has been suggested by MacMahon and Gonzalez (1997), and calculations for the magnetic cloud event of January 1997 support this hypothesis. For this event, the partitioning was $30 \%, 22 \%$ and $47 \%$, for the ring current, particle heating and Joule heating, respectively ( $\mathrm{Lu}$ et al., 1998). The consistent theme of all studies is that Joule heating is the most significant energy deposition process in the high-latitude ionosphere-thermosphere system.

There is considerable spatial structure to the Joule heating. For example, Thayer (1998) used incoherent scatter radar data to show that there was considerable vertical structure. There is also considerable longitudinal structure; Anderson et al. (1998) quote power dissipation rates of 9.2, 6.6, 7.7 $\mathrm{GW} \mathrm{h}^{-1}$ at midnight, in the early morning, and noon, respectively, which is about three times greater than the heating in the late afternoon.

The consequences of Joule heating for the ionosphere and thermosphere are very significant indeed, and global in nature. For example, Joule heating causes ion upwelling (Kivanc and Heelis, 1999), gravity waves (Williams et al., 1988; Buonsanto et al., 1999; Balthazor et al., 1997), winds, which in turn change the F-region electron concentrations (Emery et al., 1999) and thermospheric composition (Hecht et al., 1999; Mikhailov and Foster, 1997).

Joule heating depends upon the product of the ionospheric conductivity tensor and the square of the electric field in the rest frame of the neutral atmosphere. The neutral winds are 


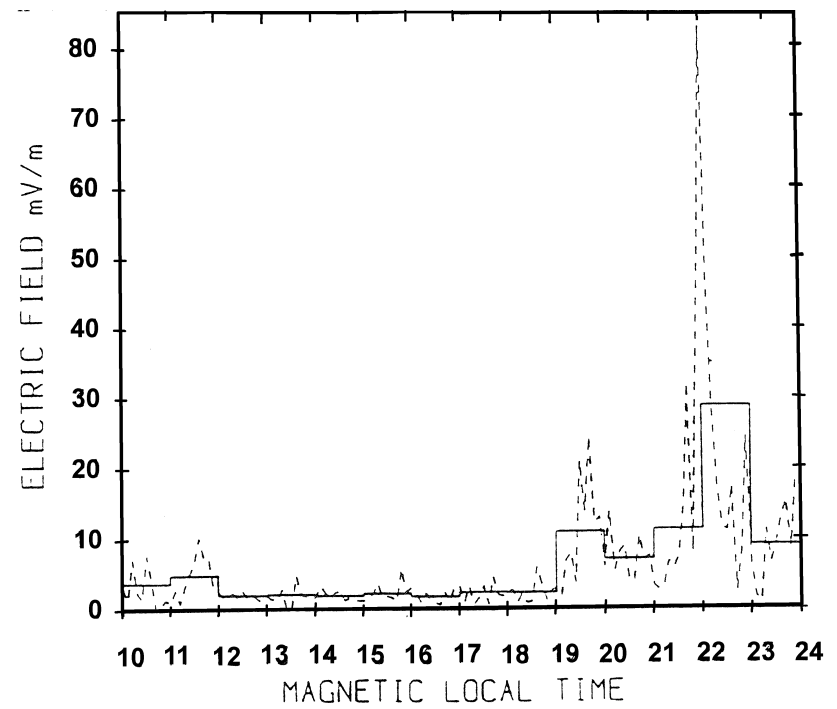

Fig. 1. The 6-minute values (E6) (broken line) and 60-minute averages (E60) (solid line) of the electric field over Troms $\varnothing$, Norway as measured by the EISCAT radar on 5 September 1989. Magnetic Local Time is about UT+1.

typically $100-200 \mathrm{~ms}^{-1}$, and their role in Joule heating is usually ignored at high latitudes, as the plasma velocities exceed the neutral velocities by a significant margin. However, Thayer (1998) has demonstrated that significant errors can arise with this assumption.

In models of the coupled ionosphere-thermosphere system, a simplifying assumption that is frequently made is that the electric field is comparatively smooth both in space and time. Typical model electric fields (e.g. Heelis et al., 1982; Foster et al., 1986) can be considered to be hourly-average values. Codrescu et al. (1995) pointed out that the highlatitude electric field is highly variable, and hence the square of the average electric field is always substantially less than the average of the square of the electric field. These authors carried out a numerical experiment using a short period of data from Millstone Hill Incoherent Scatter Radar. This showed that the Joule heating can be underestimated by 30 $230 \%$, depending exactly upon the assumptions made in the model calculations. Codrescu et al. (2000) have extended the analysis to provide variations in electric fields as a function of latitude, time and geomagnetic activity. They show that plasma velocity and its standard variation demonstrate considerable variation in space and MLT for both disturbed and moderate conditions.

In this paper, we expand upon the general approach of Codrescu et al. $(1995,2000)$ by further examining some of the consequences of assuming that the electric field is an hourly-average. First, we estimate typical variations of electric fields using data collected by the European Incoherent Scatter (EISCAT) radar (Rishbeth and Williams, 1984). The results are compared with those of Codrescu et al. (2000). We then use these findings to modify the input parameters to the coupled thermosphere-ionosphere-plasmasphere model
Table 1. $\epsilon_{6}$ as a function of magnetic local time (MLT)

\begin{tabular}{lcccccccc}
\hline MLT & $2-4$ & $5-7$ & $8-10$ & $11-13$ & $14-16$ & $17-19$ & $20-22$ & $23-1$ \\
\hline $\begin{array}{l}\text { Data } \\
\text { points }\end{array}$ & 91 & 77 & 80 & 94 & 111 & 104 & 94 & 94 \\
Median & 1.12 & 1.16 & 1.15 & 1.12 & 1.12 & 1.08 & 1.18 & 1.18 \\
$\begin{array}{l}\text { Lower } \\
\text { quartile }\end{array}$ & 1.07 & 1.10 & 1.08 & 1.07 & 1.06 & 1.03 & 1.09 & 1.10 \\
$\begin{array}{l}\text { Upper } \\
\text { quartile }\end{array}$ & 1.27 & 1.32 & 1.29 & 1.24 & 1.21 & 1.18 & 1.28 & 1.27 \\
Mean & 1.19 & 1.25 & 1.26 & 1.26 & 1.20 & 1.16 & 1.21 & 1.24 \\
\hline
\end{tabular}

known as CTIP (Millward et al., 1996) to determine both the thermospheric and ionospheric consequences of using a more realistic electric field description. We find that the peak electron concentration of the F-region $(\mathrm{NmF} 2)$, the composition of the thermosphere and the height of the ionosphere are all significantly affected. Finally, we discuss some limitations of the present approach.

\section{EISCAT data analysis}

The EISCAT radar operates in two generic modes, known as special and common programmes. The latter consists of a small number of experimental modes that are run routinely over an extended interval and thus provide an excellent data base for long-term studies of the ionosphere. In this study, we use data from the field-aligned position from the Common Programme 2 sounding mode. The tri-static plasma drift measurements provide data from all three receiving sites at the $279 \mathrm{~km}$ altitude (i.e. in the F-region, where plasma can be considered to $\boldsymbol{E} \times \boldsymbol{B}$ drift). This plasma velocity measurement can be readily converted to an electric field. This sounding mode has an integration time of $\sim 1.5$ minutes and a cycle time of 6 minutes.

We have used $745 \mathrm{~h}$ of data collected over a four-year period from February 1987 through to February 1991. Jones et al. (1986) showed that typical errors in the plasma motion from EISCAT converted into an electric field uncertainty of $\pm 3 \mathrm{mV} \mathrm{m}^{-1}$. For typical electric fields $\left(\sim 30 \mathrm{mV} \mathrm{m}^{-1}\right)$, this converts to $\sim \pm 10 \%$ error, and about $\pm 15 \%$ in Joule heating for individual measurements. However, since we use an extensive data set, these uncertainties should cancel out provided that there are no systematic errors.

We have defined an electric field parameter, E6, as the (tristatic) electric field measured in the field-aligned position, which is determined every 6 minutes. E60 is the average of 10 E6 values, and hence has a resolution of $1 \mathrm{~h}$. The difference between E6 and E60 is demonstrated in Fig. 1 which shows the two parameters for the interval 1000-2400 MLT on 5 September 1989. During the interval 1200-1800 MLT, the values of both E6 and E60 are small (a few $\mathrm{mV} \mathrm{m}^{-1}$ ). There is a sharp rise in both parameters near 1900 MLT, when EISCAT enters the auroral oval under moderate mag- 


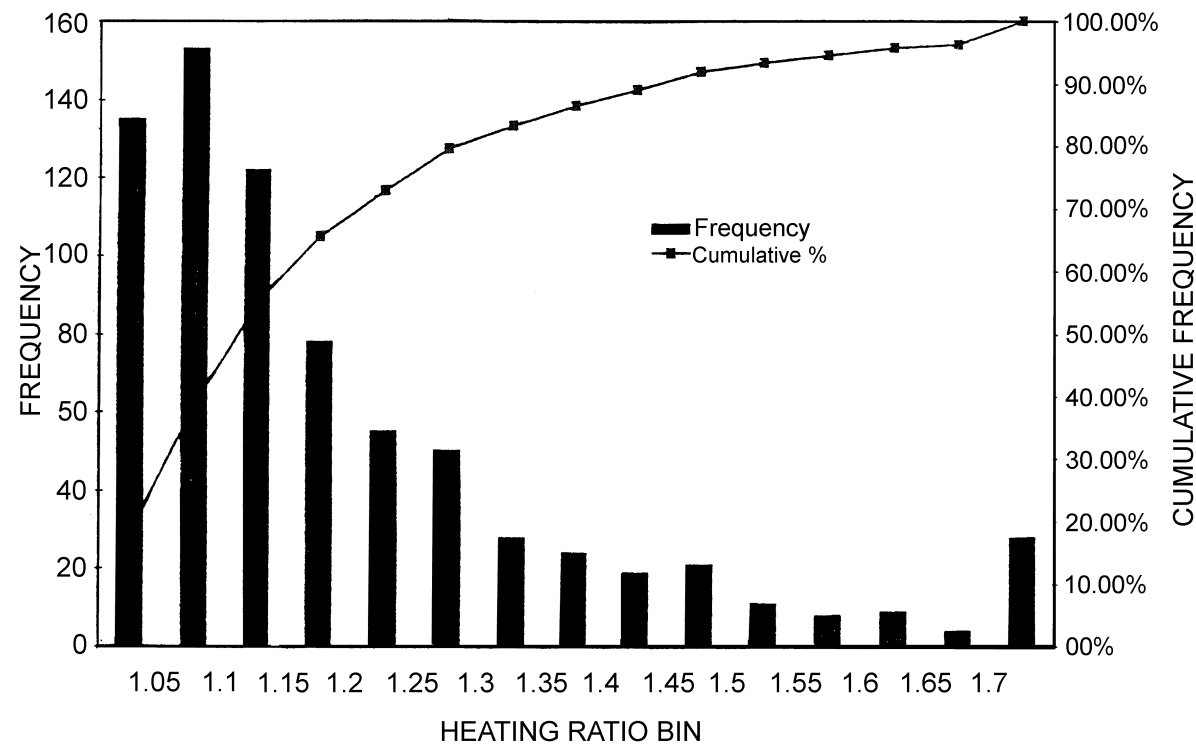

Fig. 2. The frequency distribution of $\epsilon_{6}$, the ratio of Joule heating determined using 6-minute values to that determined from hourly averages for the entire data set. netic conditions, and it remains within the oval until about 0500 MLT. The most striking difference occurs near 2200 MLT when the E6 value reaches $80 \mathrm{mV} \mathrm{m}^{-1}$, which is about four times greater than the $\mathrm{E} 60$ value at this time.

We have derived the Joule heating by using both E6 and E60 values and by using the corresponding values of conductivity derived from CTIP (see Sect. 3 for more details of CTIP) and ignoring the effects of neutral winds. For convenience, we use the parameter, $\epsilon_{6}$, which is the ratio of the average of ten 6-minute Joule heating values and the E60 value for that hour. In Fig. 2, we present the values of $\epsilon_{6}$ for the entire data set described above. The mean value of $\epsilon_{6}$ is 1.22 indicating that the Joule heating would be underestimated by $22 \%$. The median value of the distribution in Fig. 2 is 1.14, and the lower and upper quartile values are 1.07 and 1.22, respectively.

We have examined the parameter $\epsilon_{6}$ in three seasons. Summer was defined as running from May to August, winter was from November until February, and equinox included the remaining four months. We found that the median $\epsilon_{6}$ values were very similar with values of $1.15,1.13$ and 1.12 for winter, equinox and summer, respectively. The inter-quartile ranges were very similar in all three seasons as well. Hence, we conclude that there is no significant seasonal variation in $\epsilon_{6}$.

In a similar manner, we have examined the variations of $\epsilon_{6}$ as a function of the daily values of the $F 10.7 \mathrm{~cm}$ solar flux index (Fig. 3). We have determined the median value for four subsets of the data: F10.7 < 100, $100<\mathrm{F} 10.7<150$, $150<$ F10.7 $<200$, and F10.7 $>200$. We find that the median values of these subsets are 1.11, 1.10, 1.16 and 1.13 with very similar inter-quartile ranges. Thus, we conclude that there is no significant solar cycle variation in $\epsilon_{6}$.

The magnetic index $K p$ has some limitations when considering high-latitude phenomena but we have used it in this study due to of its ready availability. The distribution of $\epsilon_{6}$ as a function of $K p$ is shown in Fig. 4. Again, the data have been considered in four subsets: $K p<2,2<K p<4$, $4<K p<6$, and $K p>6$. The median values of these four subsets are $1.12,1.14,1.13$ and 1.14 , respectively, with very similar inter-quartile ranges. We conclude that $\epsilon_{6}$ has little dependence on magnetic activity.

EISCAT is located at the $67^{\circ} \mathrm{E}$ magnetic latitude, and hence, is likely to enter and exit the auroral oval each day, except under the most extreme geomagnetic conditions. During very quiet times, EISCAT may remain equatorward of the oval all day, and during very disturbed times, it may enter the polar cap near magnetic midnight. Therefore, we have investigated the variation of $\epsilon_{6}$ as a function of MLT. We divided the day into 83 -h time bins, and then determined the median, and the upper and lower quartile values. The results are presented in Table 1 which shows that there may be a modest diurnal variation with maximum values of $\epsilon_{6}$ near midnight, and minimum values in the late afternoon. Also, the mean value of $\epsilon_{6}$ is about $8 \%$ higher than the median value of all MLT.

We have investigated whether the value of $\epsilon_{6}$ was affected by the magnitude of the electric field but we have found no correlation. We have not presented the results of this analysis here.

In summary, we have found that the fluctuations in the Joule heating are remarkably insensitive to changes in magnetic time, magnetic activity, solar flux and the level of the electric field. These findings suggest that the fluctuations in the electric field are linearly related to the magnitude of the electric field. Also ideally, such a data set should be ordered simultaneously by the various external factors but alas, there are too few data points to give statistically significant results. 


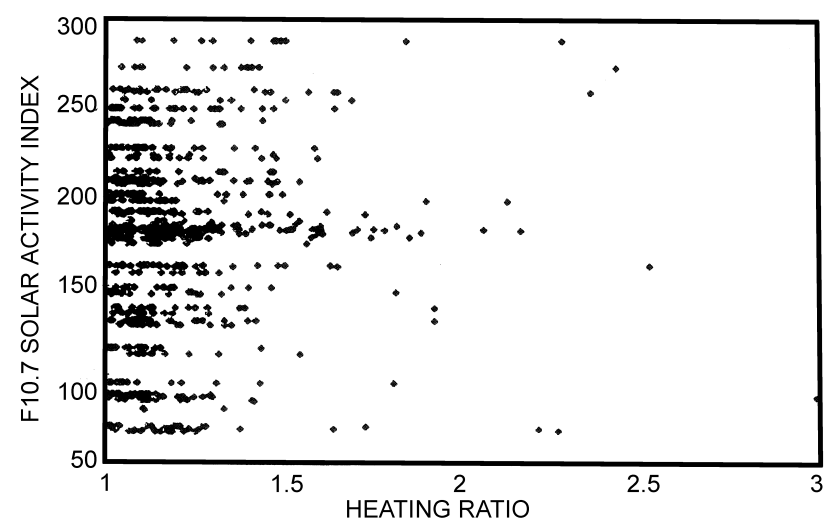

Fig. 3. $\epsilon_{6}$ as a function of the $10.7 \mathrm{~cm}$ solar radio flux.

\section{The effects of enhanced Joule heating}

In this section, we use the CTIP model (Millward et al., 1996) to explore the consequences of using a more realistic value for Joule heating. Inputs to the model are described by Fuller-Rowell et al. (1996), and by Millward et al. (1996). The magnetospheric inputs are based upon the statistical models of auroral precipitation and convection electric fields described by Fuller-Rowell and Evans (1987) and Foster et al. (1986), respectively. Both inputs are keyed to a hemispheric power index (based on the TIROS/NOAA auroral particle measurements) that is related to the $K p$ geomagnetic index (Foster et al., 1986). Typical global values of peak electron concentration, $\mathrm{NmF} 2$, are displayed by Millward et al. (1996) for low geomagnetic activity. In the present application, the CTIP model was run for December solstice (northern winter) with a F10.7 cm index of 165 . The heating and cooling rates amendments of Wells et al. (1997) were included.

In the model, the Joule heating rate is calculated as the product of the current and the steady, but spatially-varying electric field (Fuller-Rowell et al., 1996). This is consistent with the formulation of Brekke and Kamide (1996). The calculated current takes into account the conductance that arises from the calculated plasma concentrations, so that thermosphere-ionosphere coupling is properly included (Fuller-Rowell et al., 1996).

Given that the median $\epsilon_{6}$ value was 1.14 and the mean was 1.22 , and taking into account the small diurnal variation of $\epsilon_{6}$, we have chosen to enhance all calculated Joule heating rates by $20 \%$. However, we also test the sensitivity of the CTIP results by running the model with all Joule heating rates enhanced by $40 \%$; this value is a high extreme. We shall examine the changes to the thermosphere, including the neutral temperature $\left(T_{n}\right)$, the mean molecular mass $(M M M)$ and the meridional wind $\left(V_{x}\right)$, and the ionospheric composition and concentrations $\left(N_{e}\right)$.

As the Joule heating data were collected over EISCAT, we shall examine the model output in this region first. The absolute and relative changes in $T_{n}$ over the values relevant to

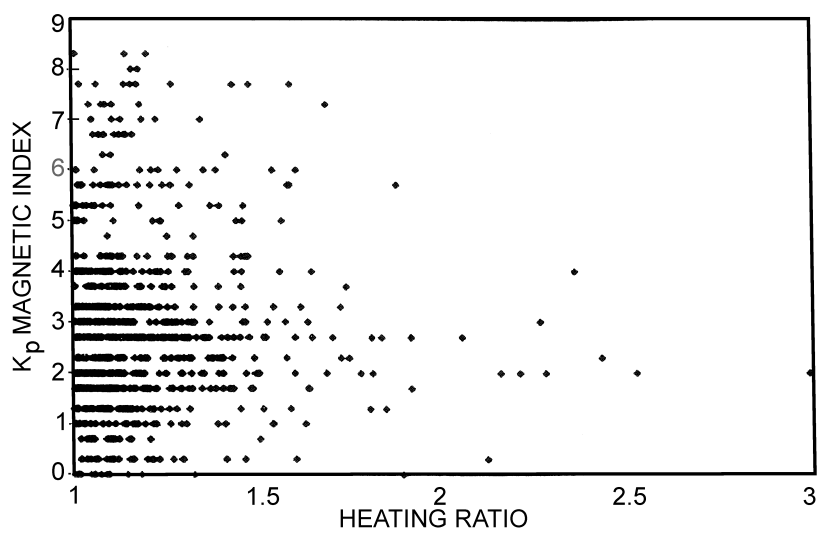

Fig. 4. $\epsilon_{6}$ as a function of the $K p$ geomagnetic index.

the unadjusted level of Joule heating are shown in Fig. 5 as a function of altitude for local noon and midnight. Increases of $10-20 \mathrm{~K}$ and $\sim 5 \mathrm{~K}$ are observed throughout the F-region during the night and day, respectively, for $\epsilon_{6}=1.4$. When $\epsilon_{6}=1.2$, there is a slight cooling at all F-region altitudes. Below $150 \mathrm{~km}$ all traces show a modest increase in temperature. The changes in temperature correspond to changes of up to about $3 \%$.

It is well-known (e.g. Burns et al., 1989) that the thermosphere becomes more (less) molecular at a fixed pressure level when $T_{n}$ increases (decreases). Figure 6 shows the corresponding increases in the $M M M$ both in absolute and relative terms for the two conditions shown in Fig. 5. The largest changes in $M M M$ occur near the $150 \mathrm{~km}$ altitude. The effects at night are about twice those of the daytime, and are about twice as large for $\epsilon_{6}=1.4$ compared with $\epsilon_{6}=1.2$. Above approximately $250 \mathrm{~km}$, changes in $M M M$ are almost zero in the daytime, and slightly positive at night.

We show in Fig. 7a the diurnal variation of the changes in $V_{x}$, as a result of the different Joule heating regimes for pressure level 13 in the CTIP model, which corresponds to an altitude near $300 \mathrm{~km}$ in the F-region peak, close to the peak electron concentration. The $V_{x}$ changes are primarily small $\left(<15 \mathrm{~ms}^{-1}\right)$ and positive, which represents an equatorward increase in the wind speed. The peak equatorward wind increases occur in the early morning and afternoon, with the minimum change occurring just before midnight. The vertical profiles (no figure) show a slow rise with altitude, with a slight peak near the $150 \mathrm{~km}$ altitude, i.e. where the maximum heating change occurs.

We now consider the ionospheric consequences of the changes in $V_{x}$, the mean molecular mass and neutral temperature. We have determined the height of the peak electron concentration in the F-region $(h m \mathrm{~F} 2)$ from the model for both the enhanced Joule heating regimes used throughout this paper. The percentage change of $h m \mathrm{~F} 2$ (Fig. 7b) is less than $3 \%$ for $\epsilon_{6}=1.4$ and below $1 \%$ for $\epsilon_{6}=1.2$. The peak value of $3 \%$ at $0800 \mathrm{LT}$ represents about a $10 \mathrm{~km}$ change in $h \mathrm{mF} 2$. Such a change is small compared to the accuracy with which $h m \mathrm{~F} 2$ can be determined from ionosonde data (Dudeney and 

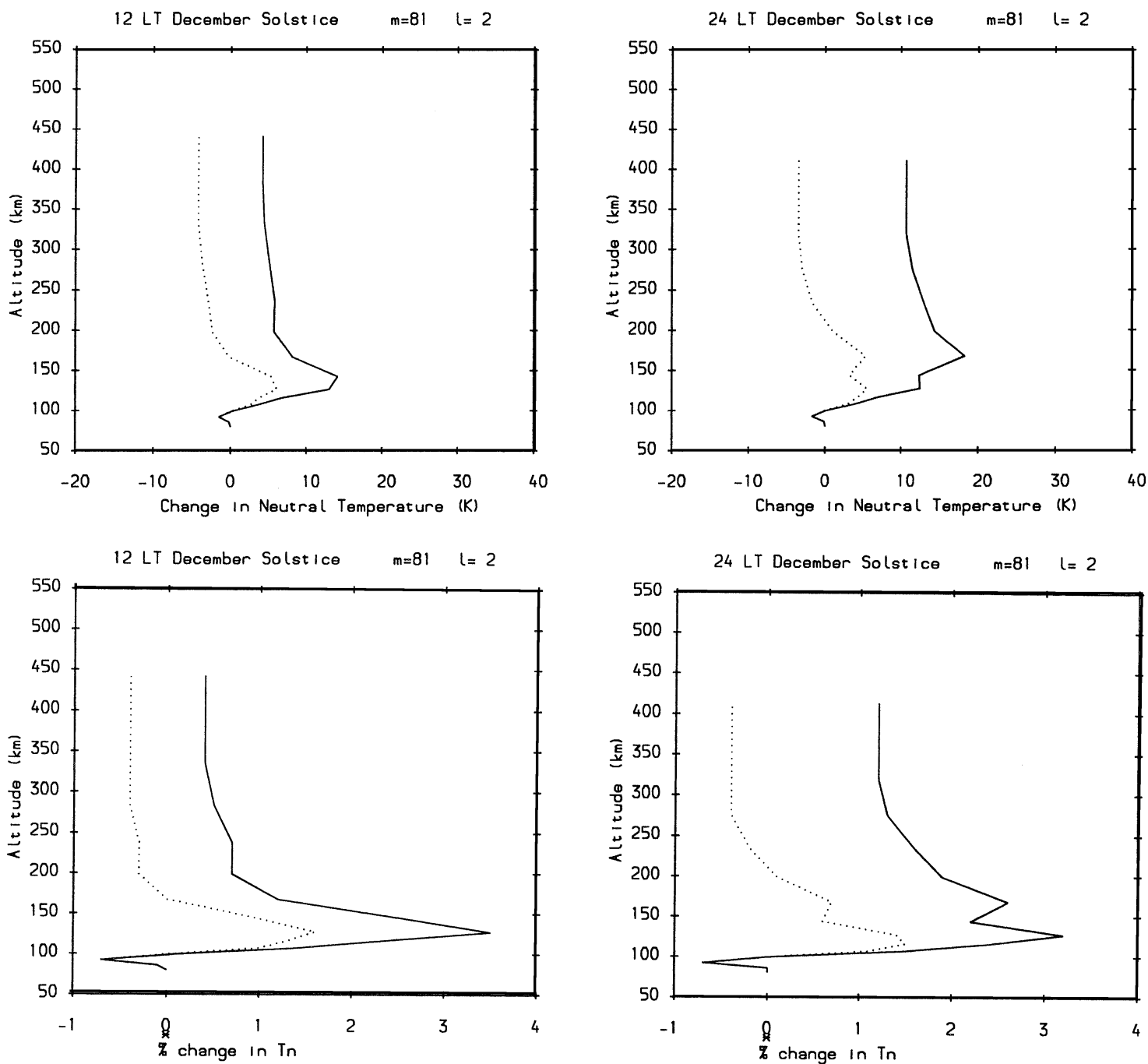

Fig. 5. Altitude profiles of the change of $T_{n}$ at local noon and midnight over EISCAT. The solid (broken) lines represent the change from $\epsilon_{6}=1$ to $\epsilon_{6}=1.4\left(\epsilon_{6}=1.2\right)$.

Kressman, 1986), but within the measurement accuracy of EISCAT itself.

The combination of the various effects described above will also affect NmF2, as illustrated in Fig. 7c. There is a reduction of NmF2 at all local times, with peak reductions near 0300 and 2000-2100 LT for both model runs. The peak decrease is $13 \%(9 \%)$ for $\epsilon_{6}=1.4\left(\epsilon_{6}=1.2\right)$. The two peaks occur when the $T_{n}$ and the $M M M$ are at their peak differences. These changes must dominate over the changes in the meridional wind which are equatorward and hence will have the tendency to move plasma to a higher altitude, where the loss rate will be reduced.

The global response to the changes in Joule heating are shown in Fig. 8 for 0000 and 1200 UT using only the model run for $\epsilon_{6}=1.4$. The figure presents results from pressure level 13 which is close to the F-region peak concentration. The results for $T_{n}$ (Fig. 8a and b) show small reductions in $T_{n}$ over the low and middle latitude (deeper blue colours) but at high latitudes in both hemispheres, an increase of between
$2-4 \%$. The magnitude of the increase is larger in the southern (summer) hemisphere by as much as a factor of 2 . Another significant difference between the two hemispheres is the increase in $T_{n}$ between $30^{\circ} \mathrm{E}-60^{\circ} \mathrm{E}$ in the summer which is absent in the winter. The corresponding plots for $M M M$ (Fig. 8c and d) show only very small effects over the entire winter (northern) hemisphere, whereas in the south, changes reach $4 \%$ in the southern high latitudes at 0000 UT. There is an enhancement of MMM between 1800-2400 LT for both runs.

The final part of Fig. 8e and $\mathrm{f}$ shows the percentage change in NmF2 for $\epsilon_{6}=1.4$ at 1200 and 2400 UT. This again illustrates that the summer hemisphere is much more dramatically affected, with the changes being about twice as large in the south than the north. The peak reduction in the south is $\sim 20 \%$, and occurs where the largest changes in the $M M M$ were observed.

The differences between the 1200 and 2400 UT plots result from the large offset of the geographic and geomagnetic 

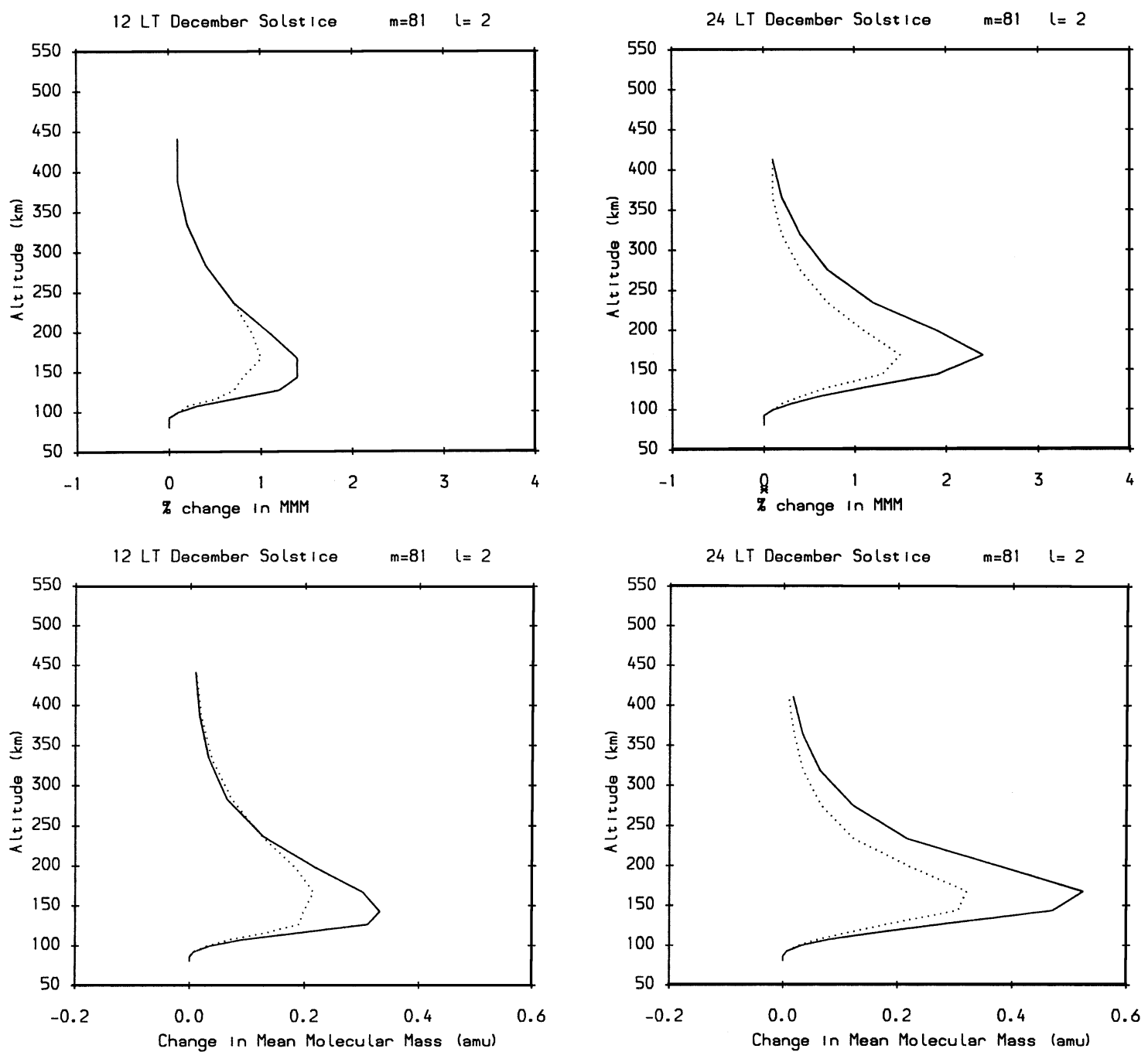

Fig. 6. Altitude profiles of the change of mean molecular mass $(M M M)$ at local noon and midnight over EISCAT. The solid (broken) lines represent the change from $\epsilon_{6}=1$ to $\epsilon_{6}=1.4\left(\epsilon_{6}=1.2\right)$.

poles in the south compared with the north (e.g. Rodger and Smith, 1989). This offset affects the way in which highlatitude energetic particle precipitation and electric fields are superimposed upon the distribution of solar-induced photoionisation. These features, in turn, affect Joule heating.

\section{Discussion}

The analysis of the electric field fluctuations over EISCAT demonstrates remarkably little variation as a function of MLT, solar flux or magnetic activity. At first glance, this might seem a surprising result and inconsistent with the results of Codrescu et al. (2000). But we have used a different analysis approach. We have essentially normalised the fluctuations by considering the ratio of the electric field variation to those of the electric field magnitude. Codrescu et al. (2000) considered the fluctuation amplitude alone. Our analysis method demonstrates the linear relationship be- tween the electric field amplitude and its variation, a result consistent with the data presented in Table 1 of Codrescu et al. (2000). The latter shows a positive linear correlation between the plasma velocity and the standard deviation that has a statistical significance of $>99.9 \%$. This is different from the solar wind where there is a power law relationship between the plasma velocity and the variations. The great advantage in finding that $\epsilon_{6}$ is essentially constant is that a single multiplication factor for Joule heating could be used for all geophysical conditions. However, we have used two values, $\epsilon_{6}=1.2$ and $\epsilon_{6}=1.4$, to capture both the average variations and the extreme variations.

Codrescu et al. (2000) also report on a seasonal variation of the amplitude of the electric field fluctuations but very careful examination of their data (their plates 1-4) shows that there is no significant variation at the $67^{\circ} \mathrm{E}$ magnetic latitude (i.e. that of EISCAT). We have used a fixed value of $\epsilon_{6}$, but our MLT study suggests a modest diurnal variation. This may be interpreted as EISCAT moving with respect to the average 
location of the auroral oval. Thus, both our study and that of Codrescu et al. (2000) have some limitations. Ordering the electric fields both in MLT and by the location of the measurement in the frame of reference of the auroral oval would be a worthwhile improvement.

The EISCAT data used in the study were the electric field values integrated for 1.5 minutes in a single location. Highertime resolution data are likely to yield more variable electric field values, and hence higher Joule heating. However, this must be counterbalanced by the fact that in general, larger electric fields are shorter-lived and occur over a smaller area. This is very well illustrated by the observations of Lanchester et al. (1997), who showed short-lived ( $<10 \mathrm{~s})$ electric fields associated with an auroral arc. The field of view of EISCAT is $\sim 3 \mathrm{~km}$ at the F-region altitudes. Typically, auroral arcs move equatorwards at $\sim 100 \mathrm{~ms}^{-1}$, and thus would remain in the beam only for a fraction of the 1.5 minute integration. Also, auroral arcs are so narrow $(\sim 100 \mathrm{~m})$ that they only fill part of the EISCAT beam at any one juncture. Finally, arcs are sufficiently narrow and far displaced from each other, that they are seldom in the EISCAT field of view. Hence, our CP2 data are likely to be a reasonable representation of the mean conditions over a $2^{\circ} \mathrm{E}$ latitude and $18^{\circ} \mathrm{E}$ longitude region which is the resolution of the CTIP model.

Throughout the calculations, we have assumed that the ionospheric conductivity does not vary on the same spatial or temporal scale as the electric field. This is obviously not true. For example, in the vicinity of an auroral arc, there is an anti-correlation between conductivity and electric field magnitudes (Lewis et al., 1994). In the auroral oval, the conductivity and the electric field vary over 1 and 2 decade ranges (1-10 mho and 5-100 $\mathrm{mV} \mathrm{m}^{-1}$ ), respectively. So although by focussing on the electric field contribution to Joule heating in this paper we have addressed the more important term, simultaneous conductivity and electric field variations would improve the parameterisation for the models. Joule heating has recently been derived using the AMIE model (e.g. Lu et al., 1996). One of the main input data sets into the model consists of the magnetometer variations which are used to determine electric field fluctuations. The disadvantage of this approach is that it is impossible to separate changes in the ionospheric conductivity from those of the electric field. In addition, the distribution of stations is not uniform in latitude or longitude. Where the models are data-sparse, a smooth model electric field is used. This study suggests that it might be better to use the $\epsilon_{6}=1.2$ factor to derive a more realistic assessment of Joule heating. This may explain why the AMIE model underestimated the temperature rise resulting from the storm of early November 1993 (Emery et al., 1999). The technique used here could be extended to add a 'correction' factor when using models such as CTIP and AMIE which tend not to completely capture the electric field variations.
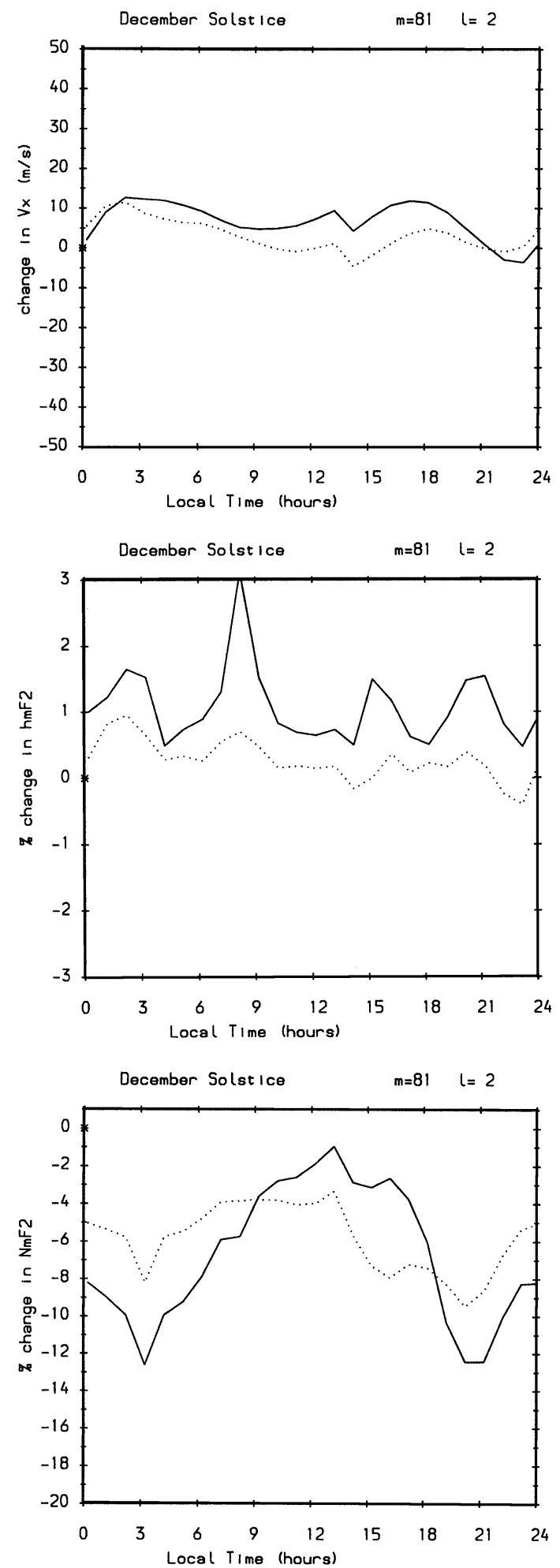

Fig. 7. (a) Change in the meridional wind velocity $\left(V_{x}\right)$ as a function of local time (positive equatorward). (b) Change in the height of the peak concentration of the F-region $(h m \mathrm{~F} 2)$; (c) Change in the peak electron concentration of the F-region $(\mathrm{NmF} 2)$. In each panel, the solid (broken) lines represent the change from $\epsilon_{6}=1$ to $\epsilon_{6}=1.4\left(\epsilon_{6}=1.2\right)$ 

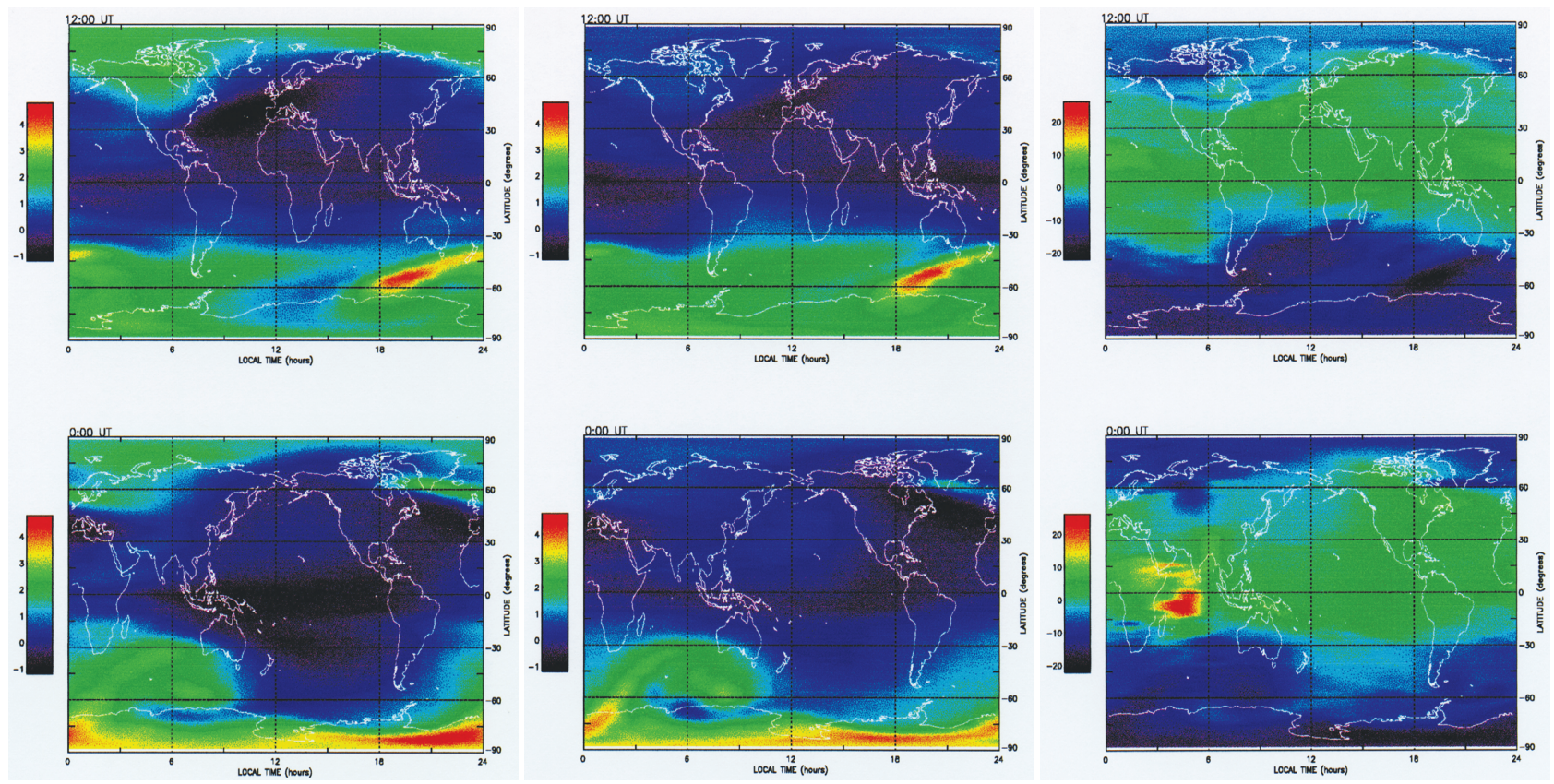

Fig. 8. The percentage change in the neutral temperature on pressure level 13 (approximately at the F-region peak) for $\epsilon_{6}=1.4$ at December solstice for (top left) 1200 UT and (bottom left) 2400 UT. The corresponding plots for mean molecular mass (MMM) (middle), and the peak concentration at F-region altitudes $(\mathrm{NmF} 2)$ (right).

\section{Conclusions}

1. We have used EISCAT radar data $\left(67^{\circ} \mathrm{E}\right.$ magnetic latitude) to quantify the underestimation of the Joule heating determined using hourly average electric field measurements data rather than 6-minute electric field measurements. This underestimation has been called $\epsilon_{6}$.

2. We have found that $\epsilon_{6}$ is remarkably independent of geomagnetic conditions, solar flux and magnetic local time. This result implies that the electric field fluctuations are linearly related to the amplitude of the electric field.

3. The median underestimation of Joule heating by using hourly averaged electric field values is $\sim 20 \%$ and with an upper extreme value of about $40 \%$ compared with that determined using 6-minute values.

4. We have shown that enhanced Joule heating causes changes both in the local and global ionosphere and thermosphere. In general, the neutral temperatures, mean molecular mass, meridional wind and height of the peak of the F-region electron concentration are all affected by a few percent. These variations cause a reduction in the peak F-region concentration of $\sim 20 \%$ in the summer hemisphere at high latitudes, and about half of this level in the winter hemisphere.

5. There are several limitations to the present work. For example, the size of the data set was too small to parameterise the fluctuations in the electric field by all the possible variables simultaneously (solar flux, magnetic activity, magnetic local time, electric field magnitude, etc.). We have not studied the relationship between conductivity and electric field variations. By using the EISCAT Common Programme 2 data, there is some ambiguity whether the variations of electric field are spatial or temporal; combined high-time resolution CUTLASS and EISCAT observations of the common volume would address this problem. These would be areas that would justify further study.

Acknowledgements. This work was carried out while G. D. Wells was supported by a PPARC CASE studentship. The work described in this paper does not represent the views of BAE. EISCAT is an association of the national scientific agencies of Finland, France, Germany, Japan, Norway, Sweden and the United Kingdom. The data were kindly provided by Dr. T. S. Virdi, University of Wales at Aberystwyth.

Topical Editor M. Lester thanks J. J. Sojka and another referee for their help in evaluating this paper.

\section{References}

Anderson, B. J., Gary, J. B., Potemra, T. A., Frahm, R. A., Sharber, J. R. and Winningham, J. D., UARS observations of Birkeland current and Joule heating rates for the November 41993 storm, J. Geophys. Res., 103, 26232-26335, 1998.

Balthazor, R. L., Moffett, R. J. and Millward, G. H., A study of the Joule and Lorentz inputs in the production of atmospheric gravity waves in the upper thermosphere, Ann. Geophysicae, 15, 779-785, 1997. 
Brekke, A. and Kamide, Y., On the relationship between Joule heating and frictional heating in the polar ionosphere, J. Atmos. Terr. Phys., 58, 139-143, 1996.

Buonsanto, M. J., Gonzalez, S. A., Pi, X., Ruohoniemi, J. M., Sulzer, M. P., Swartz, W. E., Thayer, J. P. and Yuan, D. N., Radar chain study of the May 1995 storm, J. Atmos. Sol. Terr. Phys., 61, 233-248, 1999.

Burns, A. G., Killeen, T. L. and Roble, R. G., Processes responsible for the compositional structure of the thermosphere, J. Geophys. Res., 94, 3670-3686, 1989.

Codrescu, M. V., Fuller-Rowell, T. J. and Foster, J. C., On the importance of E-field variability for Joule heating in the highlatitude thermosphere, Geophys. Res. Lett., 22, 2393-2396, 1995

Codrescu, M. V., Fuller-Rowell, T. J., Foster, J. C., Holt, J. M. and Carligia, S. J., Electric field variability associated with the Millstone Hill electric field model, J. Geophys. Res., 105, 5265$5273,2000$.

Dudeney, J. R. and Kressman, R. I., Empirical models of the electron concentration of the ionosphere and their value for radio communications purposes, Radio Sci., 21, 319-330, 1986.

Emery, B. A., Lathuilliere, C., Richards, P. G., Roble, R. G., Buonsanto, M. J., Knipp, D. J., Wilkinson, P., Sipler, D. P. and Niciejewski, R., Time dependent thermospheric neutral response to the 2-11 November storm period, J. Atmos. Sol. Terr. Phys., 61, 329-350, 1999.

Foster, J. C., Holt, J. M., Musgrove, R. M. and Evans, D. S., Ionospheric convection associated with discrete levels of particle precipitation, Geophys. Res. Lett., 13, 656-659, 1986.

Fuller-Rowell, T. J. and Evans, D. S., Height-integrated Pedersen and Hall conductivity patterns inferred from TIROS-NOAA satellite data, J. Geophys. Res., 92, 7606-7618, 1987.

Fuller-Rowell, T. J., Rees, D., Quegan, S., Moffett, R. J., Codrescu, M. V. and Millward,G. H., A Coupled Thermosphere-Ionosphere Model (CTIM), STEP handbook, Edited by R. W. Schunk, 217238, 1996

Heelis, R. A., Lowell, J. K. and Spiro, R. W., A model of the high-latitude ionospheric convection pattern, J. Geophys. Res., 87, 6339-6345, 1982.

Hecht, J. H., Christensen, A. B., Strickland, D. J., Majeed, T., Gattinger, R. L. and Jones, A. V., A comparison between auroral particle characteristics and atmospheric composition inferred from analysing optical emission measurements alone and in combination with incoherent scatter radar measurements, J. Geophys. Res., 104, 33-44, 1999.

Jones, G. O. L., Winser, K. J. and Williams, P. J. S., Measurements of plasma velocity at different heights along a magnetic field line, J. Atmos. Terr. Phys., 48, 887-892, 1986.

Kivanc, O., and Heelis, R. A., On the relationship between horizontal velocity structure and thermal ion upwellings at high latitudes, Geophys. Res. Lett., 26, 1829-1832, 1999.

Kozyra, J. U., Jordanova, V. K., Borovsky, J. E., Thomsen, M. F., Knipp, D. J., Evans, D. S., McComas, D. J. and Cayton, T. E., Effects of a high-density plasmasheet on ring current develop- ment during the November 2-6 1993 magnetic storm, J. Geophys. Res., 103, 26285-26305, 1998.

Lanchester, B. S., Rees, M. H., Lummerzheim, D., Otto, A., Frey, H. U. and Kaila, K. U., Large fluxes of auroral electrons in filaments of 100 m width, J. Geophys. Res., 102, 9541-9748, 1997.

Lewis, R. V., Williams, P. S. J., Jones, G. O. L., Opgenoorth, H. J. and Persson, M. A. L., The electrodynamics of a drifting auroral arc, Ann. Geophysicae, 12, 478-480, 1994.

Lu, G., Emery, B. A., Rodger, A. S., Lester, M., Taylor, J. R., Evans, D. S., Ruohoniemi, J. M., Denig, W. F., de la Beaujardiere, O., Frahm, R. A., Winningham, J. D. and Chenette, D. L., Highlatitude ionospheric electrodynamics as determined by the assimilative mapping of ionospheric electrodynamics mapping procedure for the conjunctive SUNDIAL ATLAS/ GEM period of March 28-29, 1992, J. Geophys. Res., 101, 26697-26718, 1996.

Lu, G. and 22 other authors, Global energy deposition during the January 1997 magnetic cloud event, J. Geophys. Res., 103, 11685-11694, 1998.

MacMahon, R. M. and Gonzalez, W. D., Energetics during the main phase of geomagnetic superstorms, J. Geophys. Res., 102, 14199-14207, 1997.

Mikhailov, A. V. and Foster, J. C., Daytime thermosphere above Millstone Hill during severe geomagnetic storms, J. Geophys. Res., 102, 17275-17282, 1997.

Millward, G. H., Moffett, R. J., Quegan, S. and Fuller-Rowell, T. J., A Coupled Thermosphere-Ionosphere-Plasmasphere model, CTIP, STEP Handbook, Ed. R. W. Schunk, 239-279, 1996.

Rishbeth, H. and Williams, P. J. S., The EISCAT ionospheric radar: the system and its early results, Q. J. Roy. Ast. Soc., 26, 478, 1984.

Rodger, A. S. and Smith, A. J., Antarctic studies of the coupled ionosphere-magnetosphere system, Phil. Trans. Royal Soc. A, 328, 271-287, 1989.

Sharber, J. R., Frahm, R. A., Link, R., Crowley, G., Winningham, J. D., Gaines, E. E., Nightingale, R. W., Chenette, D. L., Andersen, B. J. and Gurgiolo, C. A., UARS particle environment monitor observations during the November 1993 storm: auroral morphology, spectral characterization and energy deposition, J. Geophys. Res., 103, 26307-26322, 1998.

Thayer, J. P., Height-resolved Joule heating rates in the high-latitude $\mathrm{E}$ region and the influence of neutral winds, J. Geophys. Res., 103, 471-487, 1998.

Wells, G. D., Rodger, A. S., Moffett, R. J., Bailey, G. J. and FullerRowell, T. J., The effects of nitric oxide cooling and the photodissociation of molecular oxygen on the thermosphere/ionosphere system over Argentine Islands, Ann. Geophysicae, 15, 355-365, 1997.

Williams, P. J. S., Crowley, G., Schlegel, K., Virdi, T. S., McCrea, I., Watkins, G., Wade, N., Hargreaves, J. K., Lachlan-Cope, T., Muller, H., Baldwin, J. E., Warner, P., van Eyken, A. P., Hapgood, M. A. and Rodger, A. S., The generation and propagation of atmospheric gravity waves observed during the Worldwide Atmospheric Gravity-wave Study (WAGS), J. Atmos. Terr. Phys., 50, 323-338, 1988. 